\title{
In search of sticky protocols
}

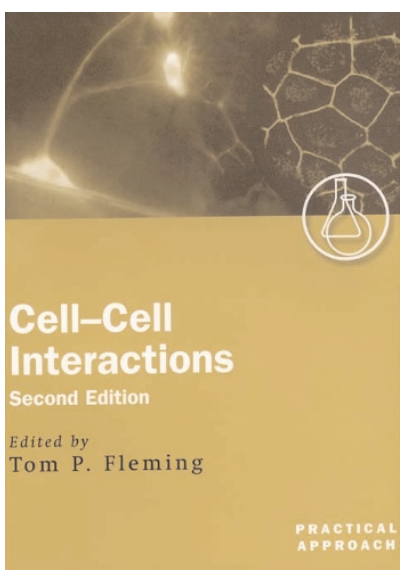

\author{
Cell-Cell Interactions \\ edited by Tom Fleming \\ Paperback $\cdot 2002$ \\ Oxford University Press, £35/\$60 \\ Frans Van Roy
}

C ell-cell adhesive interactions are responsible for making us different from unicellular prokaryotes and protists, and this difference is huge indeed. Although signalling pathways and generegulatory mechanisms are found in all living organisms, they can be extremely elaborate and plentiful once cells are interacting with their neighbours within an organism, either indirectly by virtue of secreted (soluble or insoluble) molecules or directly by specialized cell-cell contacts. My decision to start research on cell-cell adhesion and its defects in human cancer dates back to the late 1980s, when the first edition of Cell-Cell Interactions appeared in the Practical Approach Series. Tom Fleming is now in charge of a second edition, which is the 256th volume in this series, which is advertised as 'the world's leading lab guides'.

At any time, my research can benefit from a suitable new model system or assay; or other readers, who are completely new to this field, may desire more comprehensive information. Is this Practical Approach volume the book that fullfils the current needs of both groups? At first glance it looks that way - the ten chapters, written by experts in cell-cell interactions, deal with a variety of cell-cell junctions (adherens-, gap- and tight- junctions), a variety of cell types (epithelial, endothelial, leukocyte, neural and early embryonic), a variety of organisms (mammalian, Drosophila melanogaster and Xenopus laevis), and of course a multitude of protocols. In that respect, the book follows the well-known style of this series. All chapters are individually easy to read, even after a long tiring day, and the authors avoid the potentially boring nature characteristic of so many molecular 'cookery books' by nicely boxing the over 100 stepby-step protocols without overloading the essay-like text. So this volume fits well on the shelves reserved for the Practical Approach Series in each professional scientific library.

But if one starts to compare more carefully the ten chapters with each other, as well as with other sources of protocols and practical hints, one is faced with intrinsic heterogeneity and also with some bias. Gap and tight junctions seem to be well covered in two chapters that discuss suitable model systems and specialized approaches to analyse and manipulate these junctions. In contrast, a cadherin/keratinocyte chapter mainly deals with general cell biology and biochemistry. The more specialized protocol in this chapter is microinjection, even though one would expect cell-cell aggregation assays, three-dimensional skin models and so on. The leukocyte chapter starts with a concise, though informative, overview of the molecular players in leukocyte cell-cell contacts. It is a pity that the the editor did not insist on such an approach with all the contributions. Considering the lack of uniformity, a chapter that synthesized the molecular diversity of cell-cell adhesion molecules, as well as the more appropriate model systems and cell types involved would have been welcome. For instance, because desmosomes are completely neglected in this volume, the layman will either remain ignorant or believe they are not important at all. In a chapter devoted to tight-junction protein expression in early Xenopus development, both the Xenopus technology and general biochemistry, such as glutathioneS-transferase pull-down assays, are presented in detail. But someone experienced in Xenopus will not find new tricks to study cell-cell adhesion in this useful animal model. People completely inexperienced with Xenopus biology might find a Practical Approach volume exclusively devoted to Xenopus more helpful. Unfortunately this volume, in contrast to one for Drosophila, does not exist. Interestingly, the Drosophila chapter in Fleming's book approaches the difficulty of combining general information on the model with specialized information on cell-cell contacts by starting with a list of informative books and URLs 'for the absolute (Drosophila) beginner'. The model organism Caenorhabditis elegans is missing, a shame considering that its genome is fully sequenced, and the fact that interesting cell-cell adhesion research is carried out in the worm. In contrast, the specialized adhesions between oocytes and granulosa cells, between mouse blastocysts, and between human embryonic and endometrial cells are covered in an expert way by three chapters, which I feel were slightly too exhaustive. There could have been less on this, and the space used to expand the informative but too short chapter on endothelial cells, or something on neural cells in the mammalian brain could have been added, or important studies on intracellular signaling and cell differentiation as a function of specialized cell-cell interaction, for example by gene knockout experiments, might have been included.

In conclusion, the eager reader with emerging interests in cell-cell interactions would have been better served by a better representative selection of model systems and specific adhesion-related protocols, as well as by an introductory overview chapter. In his preface to the book, Fleming sighs and says that putting together a comprehensive synthesis of all new advances in methodologies for investigating cell-cell interactions is very difficult and probably unproductive. I believe it would be productive to focus on protocols covering real cell-cell interactions. After all, there are many good resources for general procedures in molecular cell biology - for example, the very useful Practical Approach Protocols Online is offering free and unrestricted access to their protocols (www.oup.co.uk/academic/science/biochemistry/pas/online/). Finally, Oxford University Press might further improve the accessibility of the numerous protocols ever published in the Practical Approach Series by compiling a suitable online index.

Frans Van Roy is in the VIB-Ghent University, Ledeganckstraat 35, B-9000 Ghent, Belgium e-mail:F.VanRoy@dmb.rug.ac.be 